\title{
Analytical description of physical and technical parameters of a bending reinforced concrete structure, influencing reinforcement fire resistance
}

\author{
Nikolay Ilyin ${ }^{1}$, Denis Panfilov ${ }^{1, *}$, and Pavel Gorshkalev ${ }^{1}$ \\ ${ }^{1}$ Samara State Technical University, Academy of Architecture and Civil Engineering, \\ Molodogvardeyskaya St., 194, Samara, 443001, Russia
}

\begin{abstract}
The paper presents field experiments and analytical description results of physical and technical parameters of bending reinforced concrete structures and their fire resistance. The results take into account the burial depth of working reinforcement, the thermo-diffusion value of protective layer concrete, the degree of reinforcement fire resistance, the nominal diameter of working reinforcement. The degree of reinforcement fire resistance is characterized by the thickness of the protective layer of concrete that changes its size and thermal characteristics in conditions of high temperatures, corrected for the conditions of the center of gravity in the reinforcement cross-section heating up. The study reveals a mathematical description of the indicators, which take into account the value of concrete thermo-diffusion reduced coefficient, intensity of force tension in working reinforcement and the size of its diameter. Analytical functions are derived for these indicators. This research results can be used for making computer algorithms and programs to calculate design fire resistance of bending reinforced concrete constructions of buildings and constructions.
\end{abstract}

\section{Introduction}

The paper an analytical description of physical and technical characteristics of bending reinforced concrete structures influencing their design fire resistance. These characteristics include the laying depth of the working reinforcement, the degree of concrete thermal diffusion, the degree of reinforcement fire resistance, the working reinforcement nominal diameter.

\section{Materials and methods}

According to the loss of its load bearing capacity $\left(F_{u z}\right.$, min), the degree of bending structures designed limits of fire resistance depends on the intensity of reinforcement initial

\footnotetext{
*Corresponding author: panda-w800i@yandex.ru
} 
stresses form the test load, the degree of reinforcement fire resistance and the static scheme of element work, i.e

$$
F_{u z}=f\left(J_{\sigma s} ; a_{B s} ; C_{m}\right)
$$

where $J_{\sigma s}$ is the intensity of stresses in the reinforcement from the current load $(0 \div 1) ; a_{e s}$ is reinforcement fire protection with concrete, $m m ; C_{m}$ is the indicator of the static scheme of reinforced concrete structure work.

The degree of reinforcement fire resistance is influenced by the thickness of the concrete protective layer, its thermos-physical characteristics, the diameter of the reinforcement, the heating scheme of the reinforcement bars in the element cross-section, i.e.

$$
a_{b s}=f\left(U ; D_{b r} ; d_{s} ; C_{n}\right)
$$

where $U$ is the thickness of the concrete protective layer, $m m ; D_{b r}$ is the indicator of concrete thermal diffusion, $\mathrm{mm}^{2} / \mathrm{min} ; d_{s}$ is the diameter of the working reinforcement, $\mathrm{mm}$; $C_{n}$ is the indicator of the heating scheme of the reinforcement bars in the element crosssection.

The influence of these physical and technical characteristics on the values of variables $J_{\sigma s}$ and $a_{e s}$ can be taken into account by the following corresponding indicators:

$$
k_{a} ; k_{\delta} ; k_{f} ; k_{m} ; k_{q} ;
$$

where $k_{a}$ is the indicator that takes into account the axial distance value; $k_{\delta}$ is the indicator that takes into account the type of concrete according to its diffusion characteristics; $k_{f}$ is the indicator that takes into account the diameter of the working reinforcement; $k_{m}$ is the indicator, taking into account the static scheme of the bending structure work; $k_{q}$ is the indicator, taking into account the heating scheme of the reinforcement bars in the crosssection.

\section{Results}

\subsection{Initial intensity of load bearing stresses in the working reinforcement}

The initial intensity of load bearing stresses in the working reinforcement before the fire effect is calculated by the formula:

$$
J_{\sigma s}=\sigma_{s n} / R_{s n}
$$

where $\sigma_{s n}$ are main stresses in the reinforcement from the test loading, $M P a ; R_{s n}$ is reinforcement normative resistance to stretching, $M P a$.

\subsection{Influence of the reinforcement diameter on the bending structure fire resistance}

Increase in reinforcement diameter gives rise to the bending structure fire resistance However, this increase is negligible. E.g. at $a=40 \mathrm{~mm}$ and diameter of reinforcement $d_{1}=10 \mathrm{~mm}$, the heating time of the section center is $\tau_{1}=33 \mathrm{~min} ;$ at $d_{2}=20 \mathrm{~mm} ; \tau_{1}=35 \mathrm{~min}$ (see Figure $1 ; a=40 m m ; t_{s, c r}=500^{\circ} \mathrm{C}$ ). 


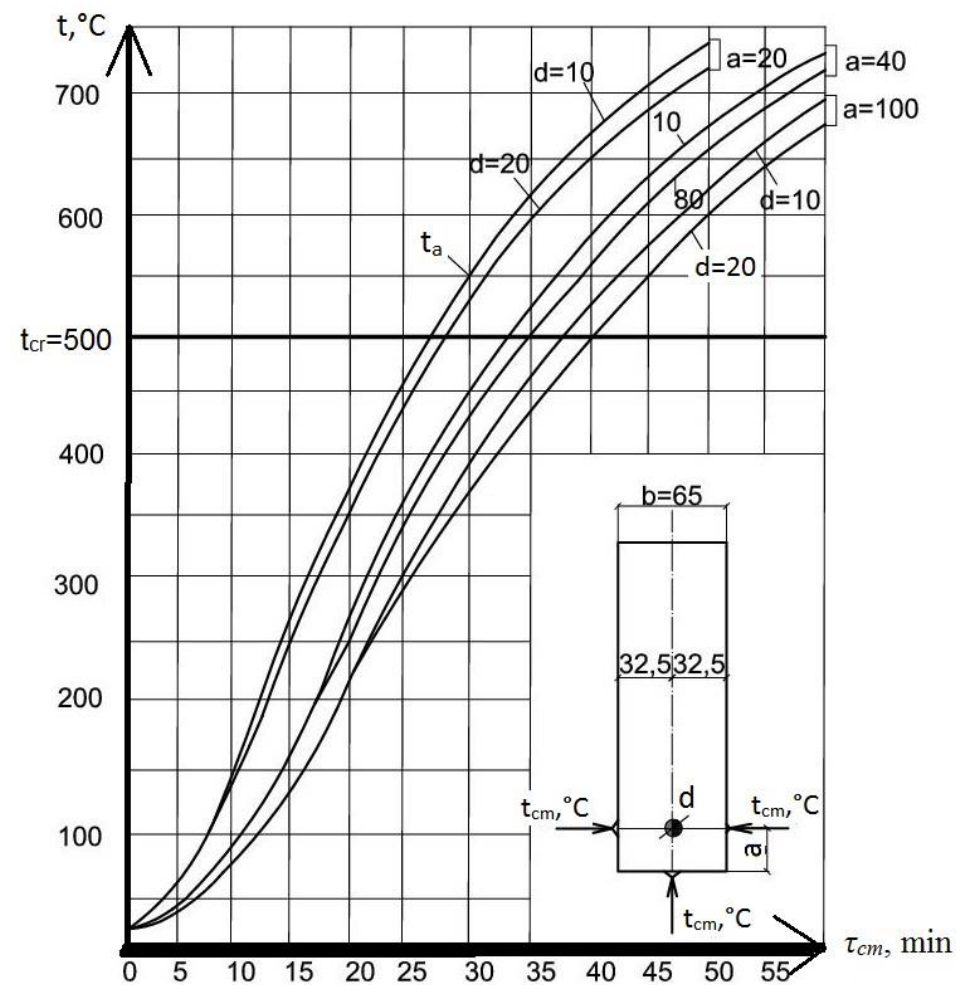

Fig. 1. Graphs of functions $t_{a r}=f\left(a, \tau_{c m}\right)$ for determining heating temperature of reinforcing bars $\varnothing 10$ and $\varnothing 20 \mathrm{~mm}$ in the edge of a beam from heavy concrete with limestone aggregate: Three-sided section heating; the edge width $B=65 \mathrm{~mm}$; reinforcement depth of coverage $a=20 ; 40$ and $100 \mathrm{~mm}$, the indicator of concrete thermal diffusion $D_{b m}=20,17 \mathrm{~mm}^{2} / \mathrm{min} ; t_{c m},{ }^{\circ} \mathrm{C}$ is the temperature of a standard fire test.

Let us calculate the following logarithmic ratio:

$$
m=\frac{\lg \left(\tau_{1} / \tau_{2}\right)}{\lg \left(d_{1} / d_{2}\right)}=\frac{\lg (33 / 35)}{\lg (10 / 20)}=0,077 ;
$$

the value of the $k_{f}$ indicator, taking into account the reinforcement diameter is

$$
k_{\varphi}=\left(\frac{d_{s}}{d_{0}}\right)^{m}=\left(\frac{d_{s}}{2}\right)^{0,077} \cong d^{0,05} ;
$$

where $d_{s}$ is the diameter of the working reinforcement, $\mathrm{cm}$.

\subsection{The account of the concrete thermal diffusion indicator}

From experimental graphs of heating of a slab with thickness of $h=60 \mathrm{~mm}$ at $\delta=20 \mathrm{~mm}$ and $t_{s, c r}=500^{\circ} \mathrm{C}$, we have $\tau_{2}=45 \min (0.75$ hour $)$ and $\tau_{2}=52,2 \min (0.87$ hour $)$ (see Figure 2 and Figure 3).

Using Formula (10), let us calculate heavy concrete diffusion, with limestone and granite, respectively: $D_{r b l}=20,17 \mathrm{~mm}^{2} / \mathrm{min} ; D_{r b 2}=22,68 \mathrm{~mm}^{2} / \mathrm{min}$.

From the obtained experimental data, we calculate the exponent: 


$$
m=\frac{\lg \left(\tau_{1} / \tau_{2}\right)}{\lg \left(D_{1} / D_{2}\right)}=\frac{\lg (52,2 / 45)}{\lg (20,17 / 22,68)}=-0,8
$$

The indicator, taking into account the value of the experimental structure concrete diffusion, equals to:

$$
k_{g}=\left(\frac{D_{r s}}{20,17}\right)^{-0,8}=10,7 / D_{r b}^{0,8}
$$

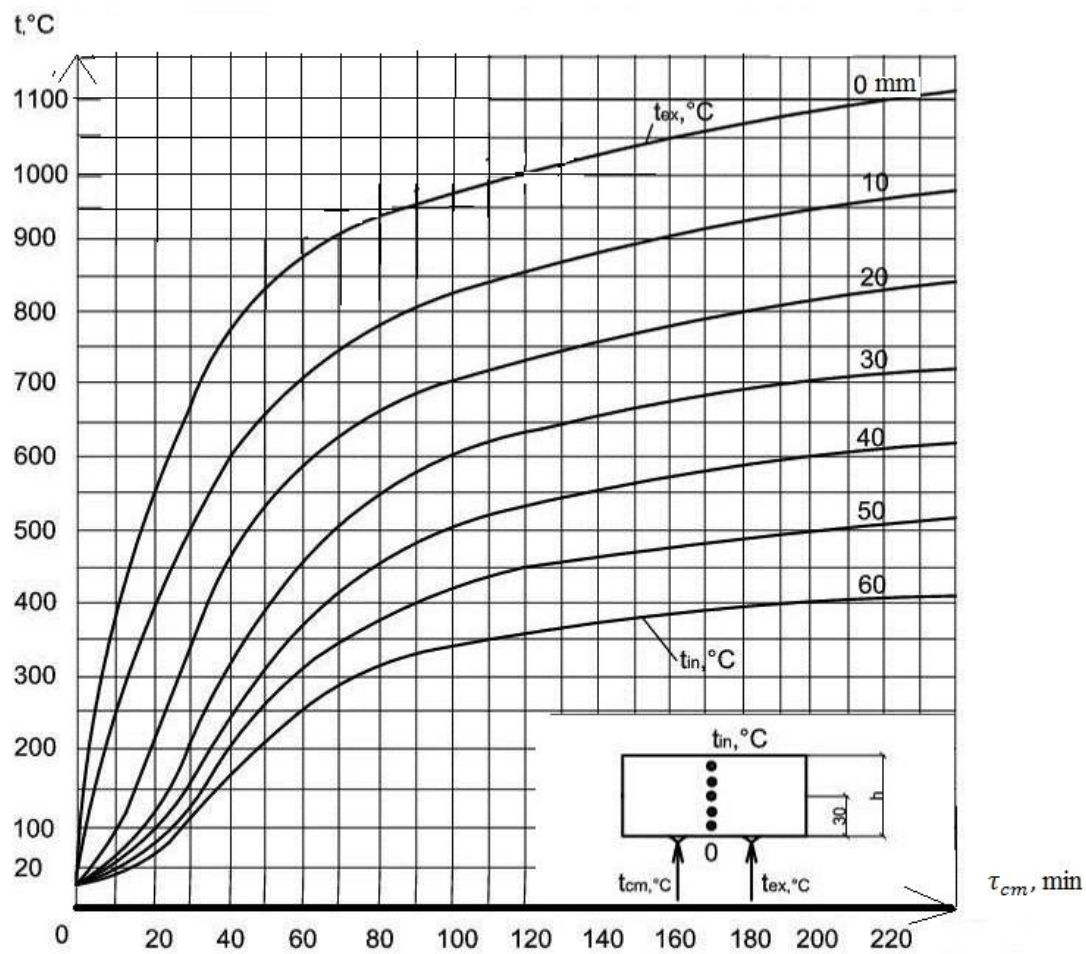

Fig. 2. Graphs of functions $t_{h r}=f\left(h, \tau_{c m}\right)$ to determine the heating temperature of the slab thickness $h=60 \mathrm{~mm}$ of heavy concrete with granite aggregate depending on the duration of standard testing, $\tau_{\mathrm{cm}}$, min: concrete density $\rho_{c}=2250 \mathrm{~kg} / \mathrm{m}^{3}$; moisture $\Omega=2 \%$; single-sided section heating; temperature registration points: $t_{e x}$ and $t_{c n},{ }^{\circ} \mathrm{C}$ - on the heated and, accordingly, unheated surface, $t_{h t},{ }^{\circ} \mathrm{C}$ - at points of the slab cross-sections, every $10 \mathrm{~mm}$ on its thickness; $t_{c m},{ }^{\circ} \mathrm{C}$ - the temperature of a standard fire test.

For reference concrete $D_{r b}=20,17 \mathrm{~mm}^{2} / \mathrm{min}$, the indicator of the physical characteristics is equal to:

$$
k_{\alpha}=\left(\frac{D_{r \beta}}{22,34}\right)^{-0,8}=12 / D_{r \beta}^{0,8}
$$

The given indicator of concrete thermal diffusion is determined by the formula: 


$$
D_{b m}=\frac{60 \cdot 10^{3} \cdot(\lambda \pm 0,45 \cdot b)}{\rho_{s} \cdot\left(c_{0}+0,45 \cdot d+\omega / 20\right)}
$$

where $\lambda_{0}$ and $b$ - are empirical numbers to calculate the thermal conductivity coefficient of construction material $w /\left(m \bullet^{\circ} \mathrm{c}\right) ; t_{m}$ - average temperature of the material along the section of the construction $\left(450^{\circ} \mathrm{C}\right) ; c_{0}$ and $d-$ are empirical numbers to calculate the specific thermal capacity of the heated material $\mathrm{kJ} /\left(\mathrm{kg} \cdot{ }^{\circ} \mathrm{C}\right) ; \omega$ - is humidity of material mass, \%; $\rho_{s}$ is average density of dry concrete, $\mathrm{kg} / \mathrm{m}^{3}$.

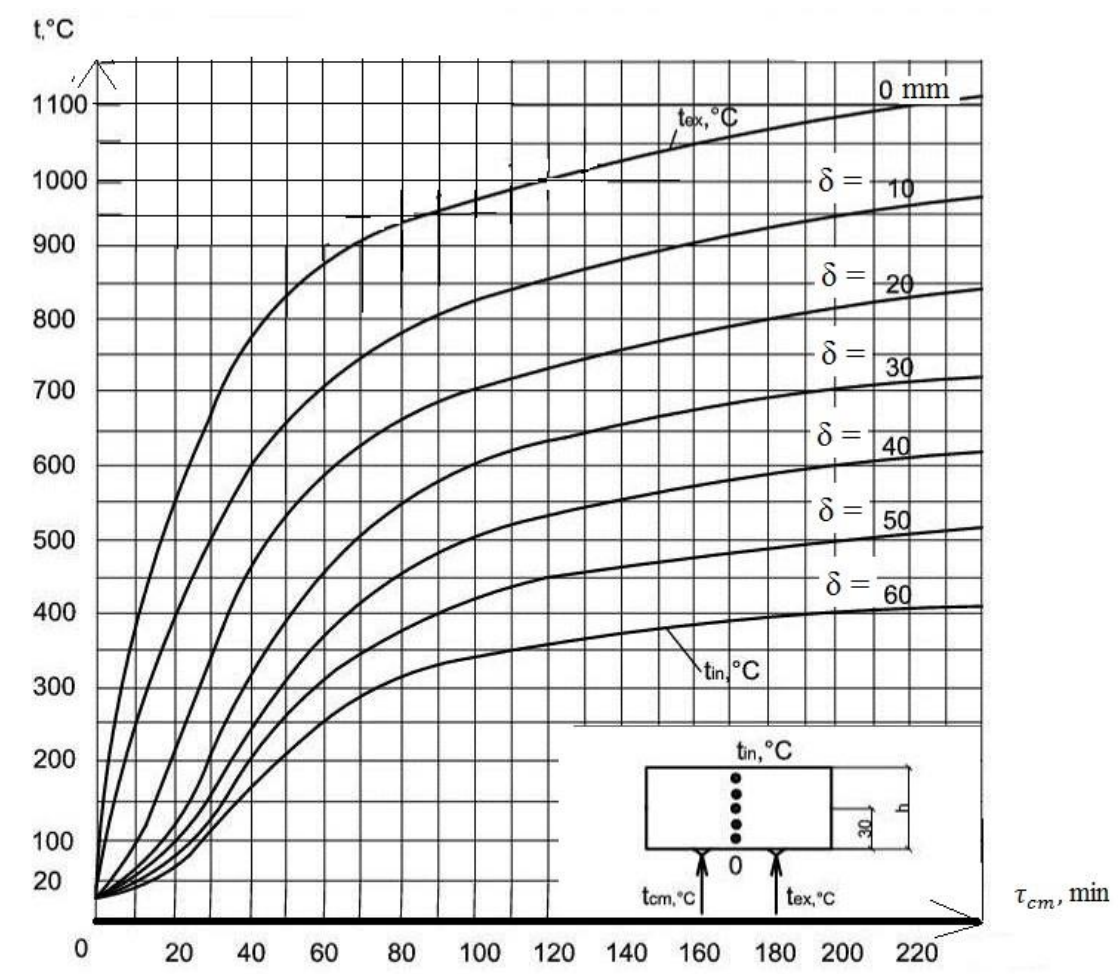

Fig. 3. The graphs of the function $t_{h r}=f\left(h, \tau_{c m}\right)$ to determine the heating temperature of the slab thickness $h=60 \mathrm{~mm}$ of heavy concrete with limestone aggregate: concrete density $\rho_{c}=2250 \mathrm{~kg} / \mathrm{m}^{3}$; moisture $\omega=2 \%$; single-sided section heating; temperature registration points: $t_{e x}$ and $t_{i n},{ }^{\circ} \mathrm{C}$ - temperature on the heated and, accordingly, unheated surface, $t_{h t},{ }^{\circ} \mathrm{C}$ - at points of the slab cross-sections spaced at intervals of $\Delta h=10 \mathrm{~mm}$ on its thickness; $t_{\mathrm{cm}},{ }^{\circ} \mathrm{C}$ - the temperature of a standard fire test.

\subsection{Degree of reinforcement fire resistance}

With the growth of the working reinforcement fire resistance, the fire resistance of the bending structure also increases. Here, under the reinforcement fire resistance we understand the thickness of the concrete protective layer, which changes its volume and thermo-technical properties at the exposure of high temperatures, with allowance for the conditions of the reinforcement cross-section heating, that is:

$$
a_{b s}=f\left(U_{s} ; d_{s} ; D_{b r} ; m_{0}\right) \text {; }
$$


substituting these variables and values of coefficients, taking into account these parameters, we obtain the value of reinforcement fire resistance at single-sided heating:

$$
a_{b s}=m_{0} \cdot\left(U_{s}+0,5 \cdot d_{s}\right) \cdot k_{d} c_{0}
$$

or

$$
\begin{aligned}
& a_{b s}=1 \cdot\left(U_{s}+0,5 \cdot d_{s}\right) \cdot 12 / D_{r b}^{0,8} \\
& a_{b s}=12 \cdot\left(U_{s}+0,5 \cdot d_{s}\right) / D_{r s}^{0,8} ;
\end{aligned}
$$

where $U_{s}$ is the thickness of the concrete protective layer, $m m ; d_{s}$ is the diameter of reinforcement, $\mathrm{mm} ; D_{r e}$ is the given indicator of concrete thermal diffusion, $\mathrm{mm}^{2} / \mathrm{min} ; \mathrm{m}_{0}$ is the coefficient of heating conditions of the reinforcement bars in the element cross-section.

The researchers used the following academic research work materials for preparing this paper: [see 1-12].

\section{Conclusion}

According to the results of this research and comparison of calculations and experimental data, we can draw the following conclusions:

1. The degree of reinforcement fire resistance is characterized by the thickness of the protective layer of concrete that changes its size and thermal characteristics in conditions of high temperatures, corrected for the conditions of the center of gravity in the reinforcement cross-section heating up.

2. The analytical equation for quantitative estimation of the reinforcement fire resistance degree is given as a function (14) of four variables.

3. The study reveals a mathematical description of the indicators, which take into account the value of concrete thermo-diffusion reduced coefficient, intensity of force tension in working reinforcement and the size of its diameter. Analytical functions $(4,6,9)$ are introduced in this study to take into account these indicators.

\section{References}

1. V.P. Bushev, V.A. Pchelintsev, V.S. Fedorenko, A.I. Yakovlev, Fire resistance of buildings (Stroiizdat, Moscow, 1970)

2. V.P. Bushev, A.I. Yakovlev, et al. Instruction on calculation of actual limits of fire resistance of reinforced concrete structures on the basis of computer application (1975)

3. I.G. Romanenkov, A.I. Yakovlev V. V. Solomonov, et al, Manual on determination of fire resistance limits of structures and groups of flammable materials (1985)

4. A.I. Yakovlev, Calculation of fire resistance of building structures (Stroiizdat, Moscow, 1988)

5. A.F. Milovanov, V.V. Solomonov, I.S. Kuznetsov et al, Manual on calculation of fire resistance and fire durability of reinforced concrete structures from heavy concrete (2008)

6. N.A. Ilyin, D.A. Panfilov, Organization standard. Determining fire resistance of reinforced concrete structures of buildings. Methodology (2015)

7. N.A. Ilyin, Consequences of fire impact on reinforced concrete structures (Stroiizdat, Moscow, 1979)

8. N.A. Ilyin, M.B. Pirogov, Patent No. 2161798 (1999) 
9. N.A. Ilyin, D.A. Panfilov, Certificate of the Russian Federation on State Registration of the program for computer No. 2015619750 (2015)

10. N.A. Ilyin, D.A. Panfilov, Patent No. 2615048 (2017)

11. N.A. Ilyin, D.A. Panfilov, E.V. Ildiyarov, S.A. Lukin, Patent No. 2639209 (2017) 